Revista Estudios, (36), 2018.

Junio 2018-Noviembre 2018

ISSN 1659-3316

Iza Villacís Víctor Adolfo

V Sección

Dossier: Repensar las humanidades: una tarea permanente

\title{
Personalismo y alteridad como base filosófica para una praxis universitaria
}

\author{
Víctor Adolfo Iza Villacís \\ Universidad Politécnica Salesiana, Ecuador \\ viza@ups.edu.ec \\ https://orcid.org/0000-0001-9834-7683
}

Recibido: 5 de marzo de 2018

Aceptado: 11 de abril de 2018

\section{Resumen}

El personalismo como base filosófica es oportuno para una reflexión desde la alteridad y la responsabilidad, desde las categorías de Emanuel Levinas, en la praxis universitaria, ya que permite realizar un análisis y un diálogo en contexto con las prácticas asociadas a la promoción humana y realizar un estudio crítico desde la realidad universitaria, la situación estudiantil, la gestión docente académica y la Institucionalidad. Se propone una revitalización a la vida juvenil no solo como profesionalización sino como sentido, el llamado a la gestión docente para salir del academicismo, la comunitariedad como elemento de alteridad que brota de la donación y por último la praxis como trascendencia ligada al servicio y transformación de la sociedad.

Palabras claves: Alteridad; persona; responsabilidad; trascendencia; universidad

\section{Personalism and alterity as a philosophical basis for a university practice}

\begin{abstract}
Personalism as a philosophical basis is appropriate for reflection from alterity and responsibility, from the categories of Emanuel Levinas, in the university praxis, since it allows an analysis and a dialogue with the context with the practices associated with human and social promotion. make a critical study from the university reality, the student situation, the teaching - academic management and the Institutionality. It proposes a revitalization of youth life not only as professionalization but as meaning, the call to teacher management to get out of academicism, community as an element of otherness that springs from donation
\end{abstract}

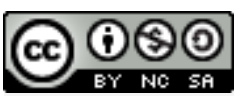

La Revista Estudios es editada por la Universidad de Costa Rica y se distribuye bajo una Licencia Creative Commons Atribución-NoComercial-CompartirIgual 3.0 Costa Rica. Para más información envíe un mensaje a 
Revista Estudios, (36), 2018.

Junio 2018-Noviembre 2018

ISSN 1659-3316

Iza Villacís Víctor Adolfo

and finally praxis as transcendence linked to service and transformation of the society.

Keywords: Alterity; person; responsibility; transcendence; university

\section{Introducción}

Comprender a Levinas como hombre de su tiempo y dueño de sus ideas, no es camino fácil, ha requerido ilustrarse primeramente en su manera de pensar y filosofar, una de las características esenciales en este punto bebe de la tradición talmúdica, y el enorme comentario de la Guemará a los textos talmúdicos (GarcíaBaró, 2007), forma antiquísima de judaísmo. No hace falta aquí poner todas las formas de judaísmo que existen, sin embargo, sabemos que para Levinas no hay una diferencia entre la teología y la filosofía, cuando existen comentarios sobre la escritura ya se hace filosofía, porque, y esta es la segunda causa, a diferencia de los griegos los judíos no generan una división entre mito y filosofía, situación que se ha venido fomentando en el mundo intelectual $y$ ha sido debate durante muchos siglos sobre razón y fe.

La segunda comprensión acerca de Levinas es su ser judío, quien vive su fe y tradición, comprendiendo su contexto y circunstancias, una religión y una experiencia con sus ritos y estudios, lo que le permite afrontar y enfrentar el mundo cuando se encuentra con la tradición intelectual de occidente, que no se contrapone en especial en su relación con Husserl sino que la puede proponer desde otra vereda, o situándose desde esta tradición Talmúdica.

Levinas es un hombre Lituano-francés que vive las crueles experiencias de la II Guerra, el horror de los campos de concentración y quien convive con el sufrimiento, el dolor y el cautiverio. Esta experiencia que si bien le marca, también lo fortalece en su filosofía. Para algunos es considerado el mayor filosofo judío del siglo XX, por su entereza y su complejidad para desarrollar la teoría del rostro, la

\section{(c) (1) (2)}

La Revista Estudios es editada por la Universidad de Costa Rica y se distribuye bajo una Licencia Creative Commons Atribución-NoComercial-CompartirIgual 3.0 Costa Rica. Para más información envíe un mensaje a revistaestudios.eeg@ucr.ac.cr. 
otredad, la mirada, la substitución, la excedencia, la trascendencia y en especial la ética como filosofía primera dándole a la vez un carácter práctico a la filosofía en el amor

Es clave su posición frente a los tipos de filosofía contemporánea, en su época (siglo XX), el "distanciamiento" de la filosofía fenomenológica que presenta en su momento Husserl, y la reflexión ontológica y existencialista del ser ahí (Dasein) de Heidegger (El Ser y el Tiempo, 1927) ir del cuidado de sí al cuidado del otro es un paso excepcional que lo da Levinas. (Locatelli, 2013)

En este apartado de comprensiones de la filosofía Levinasiana aparecen situaciones que aportan de manera significativa a la envergadura con que propone una mirada diferente en relación al evento otro y la mismidad; al ser como totalidad y al otro como infinito, dos posiciones que ponen de manifiesto su "distancia " entre las filosofías antes mencionadas.

La otredad que nace de la profunda reflexión que se hace de la mirada y del rostro marcan una distancia a lo que Jean Paul Sartre propone desde el existencialismo sobre el otro, el distinto a mí. Por supuesto la reflexión sobre la otredad no es original de Levinas, es su sentido la originalidad, es su punto de partida desde otra herencia, otra tradición lo que le marca un camino distinto y como se presenta está cargado de un sentido que debe ser comprendido desde el judaísmo.

Decir en Griego lo que se ha escrito en Hebreo, como bien lo manifiesta en su obra García-Baró, (2007) o como lo menciona Medina (2017), Decir en griego la novedad del hebreo, es un ejercicio exhausto para que lo que desea Levinas expresar pueda ser aceptado, estudiado en categorías que por tradición se hicieron desde la tradición griega, en especial en Occidente y en nuestro caso latinoamericano que ha sido asumido en esas categorías formales, de este punto se trata $\mathrm{m}\{$ as adelante en el apartado sobre la universidad.

Los términos filosóficos levinasianos se sitúan bajo el análisis de la perspectiva judía, talmúdica y de la Mishna de la cual Levinas hace uso para darle un sentido que tenga equivalente y a la vez una distinción, que no es original del mismo, sino 
que la re-vela en el sentido que las plantea, y que al situarse, pararse, frente a la filosofía occidentalista con tradiciones greco-latinas-cristianas, toman una fuerza de carácter que no se contraponen, a la forma de ver del autor de este escrito, sino que toman un sentido más amplio, o por lo menos diferente con un contenido de sentido que provoca nuevas categorías de pensamiento. (García-Baró, 2010) Levinas no busca la desestructura como es la orientación de Derrida, o el sin sentido del Nihilismo, propuesto por Nietzsche. Su propuesta filosófica va dirigida a una práctica real en la vida a través de la ética, digo practica real porque no es una situación netamente racional, sino que "golpea" y deja la sensación en la cual, quien se enfrenta a sus nuevos sentidos de comprensión, puede experimentar que había un silencio escondido que necesitaba ser nombrado. Permíta el lector la comparación parabólica con una de las escenas de la película "La vite è bella" dirigida, actuada y producida por Roberto Begnini, cuando en una de sus adivinanzas el actor da la respuesta como el silencio a "cuando me nombras dejo de existir" (Begnini, 1997). Este existir que solo puede trascender al ser nombrado, es el otro silenciado que lo nombra libertad y se puede romper son ese encantamiento al que le ha llevado la ontología y el racionalismo al ser humano y su mismidad. Esa existencia trasciende, es decir el lenguaje trasciende a su propio sentido, Levinas siempre presenta al sentido un sentido más amplio de comprensión. permite una trascendencia del ser más allá del ente Heideggeriano. La manera de exponer los mismos elementos con otro sentido es tan profunda que la misma palabra filosofía. este ejemplo es maravilloso por su sentido de amplitud, a la cual generalmente en su etimología se la comprende como el "amor a la sabiduría", situación que nace de la vertiente griega, mas en el caso de Levinas, que no busca destruir el sentido, sino que, desde él, le da mayor fortaleza, indica que la filosofía es la "sabiduría del amor", y esto nace porque la mirada no solo se queda en la vertiente griega sino que puede tener raíces en la tradición talmúdica judía. (Medina, 2017)

\section{(c) (i) (-)}

La Revista Estudios es editada por la Universidad de Costa Rica y se distribuye bajo una Licencia Creative Commons Atribución-NoComercial-CompartirIgual 3.0 Costa Rica. Para más información envíe un mensaje a 
ISSN 1659-3316
Iza Villacís Víctor Adolfo

Junio 2018-Noviembre 2018

Al proponer entonces a la "ética como filosofía primera" Levinas no solo se sitúa en la otredad, hay pensadores y filósofos que caen en este error de aventurarse fácilmente a presentar a Levinas como el filósofo del rostro (Silva, 2017). Levinas sitúa a la ética como esa fenomenología de la revelación en lenguaje de amor, que es el lenguaje pleno de la revelación del totalmente Otro en la totalidad (la mismidad, el yo) que al descubrirse en el otro no le queda otro remedio que amar (en el infinito). Al ser entonces la filosofía la sabiduría del amor, habrá que entender que el camino del humanismo, como muy bien presentan otros filósofos, estudiosos de Levinas, como el filósofo de un nuevo humanismo. Es el amor la ética para un nuevo humanismo.

Desde esta perspectiva nace esta posibilidad de comprensión de la praxis universitaria, en especial en aquellas instituciones donde el personalismo como forma de humanismo se presenta en su carácter formativo para los ciudadanos de los países latinoamericanos, desde estos presupuestos, de otredad - alteridad y responsividad - responsabilidad, se acerca este análisis de la coyuntura de la educación superior.

El método utilizado es el análisis crítico filosófico basándose en autores más contemporáneos que hacen un análisis de la realidad en los momentos actuales, donde la visión sobre el ser ha cambiado de manera drástica o espectacular, dependiendo de la óptica con la cual se aprecie. Fruto del posmodernismo y ayudados de tres autores contemporáneos, Noam Chomsky, Zigmunt Bauman, Byung - Chul Han, se puede comprender algunas características en las cuales se desenvuelve la practica educativa o a cuáles perspectivas responde. El especial carácter de Chomsky que compromete el lenguaje no como poder a la manera de Foucault (1996) sino como dominación del otro, exterminio, explotación y colonialismo mundial, un abuso enfermo del sistema económico que asesina a millones de seres humanos solo y a causa del mercado y el dinero y frente a esto la (des) educación (Chomsky, 2016). Bauman característico por la liquidez, aquello que empieza carecer de sustento, que como el agua se va de entre las manos

\section{(c) (1)(2)}

La Revista Estudios es editada por la Universidad de Costa Rica y se distribuye bajo una Licencia Creative Commons Atribución-NoComercial-CompartirIgual 3.0 Costa Rica. Para más información envíe un mensaje a 
antes de lavarnos la cara, una sociedad, una persona que respira cansancio, frente a ella la alteridad, la educación, las redes son solo meros condicionamientos que no le brindan ningún sentido a la vitalidad humana (Bauman, 2007). Y el filósofo surcoreano, que desde Alemania con fuerza abismal hace un ensayo sobre lo distinto, la expulsión, una crítica a la desalmada sociedad de la sospecha y el miedo que acaba con todo tipo de alteridad, compasión o acogida. (Han B. C., 2017).

\section{La universidad en contexto}

El ámbito universitario en Latinoamérica es diverso sin embargo hay algo que está presente en sus fundamentos y en este caso es la permanente ligación al eurocentrismo académico y al estilo norteamericano sin ser el más generalizado. Ha existido una preocupación en este sentido y algo se ha intentado para romper con esta homogenización, tal vez con una perspectiva que promueva lo andino o lo autóctono de las regiones, sin embargo, la homogenización de lo académico termina siendo una camisa de fuerza para prácticas innovadoras en las universidades $o$ en el aspecto educativo superior. Una mirada no basta, sin embargo, esa mirada es la que estandariza y condiciona los procesos a nivel internacional.

Por otro lado, están los aspectos de relación con las leyes de cada país que obligan en cierta manera a los organismos de educación superior a que sus prácticas se determinen desde lo que la ley les permite y hasta donde puedan alcanzar a desarrollar, siguiendo estos parámetros pueden ser innovadores algunos procesos pero que en la sustancial no cambia la megaestructura a la que se han sometido a los sistemas educativos.

Desde estas condiciones las Instituciones de educación superior conjugan sus mecanismos de supervivencia desde ópticas conservadoras, es decir procurando cumplir la ley, las normas y reglamentos para lo cual trabajan incansablemente por 
no cometer errores, dirigiendo un vasto esfuerzo a la recopilación de datos y evidencias que les permita seguir existiendo o por lo menos demostrando que sus prácticas están ligadas al marco jurídico vigente. Además, el sistema de mercado obliga a publicitar sus servicios ofertando carreras que se vinculan a la necesidad del mercado y no tanto a la necesidad cultural o humana. Una carrera o un posgrado debe abrirse en una universidad para que no se pierda recursos y sea económicamente rentable, eso con respecto a las universidades que no son públicas y que deben ofertar lo mejor posible sus servicios para que la rentabilidad les ayude a permanecer vigentes. Este tipo de visión mercantilista hace que se observe a los estudiantes como clientes a los cuales hay que ofertar experiencias y sensaciones de estabilidad emocional utilizando los mecanismos del marketing y la publicidad.

Así estamos frente a una universidad que ha perdido el rumbo crítico frente a la transformación de la sociedad, tratando de permanecer en el tiempo y en el espacio de la acreditación, sistemas ISSO y de calidad y mecanismos de marketing publicitario para sostenerse en el mercado y fomentar la profesionalización como mecanismo de establishment con respecto a la necesidad de una educación basada en modelos europeos o americanizados. Lejos estamos de tener una universidad menos euro centrista en contenidos y ligada a la riqueza cultural y ambiental latinoamericana.

Los desafíos propuestos en un estudio realizado por Roberto Rodríguez Gómez en el umbral del siglo XXI siguen vigentes pero incrustados en tres variantes: acometividad, relación social y profesionalización, se menciona la necesidad de un cambio profundo y significativo de la praxis educativa para una transformación social, así como políticas gubernamentales que promuevan un cambio de modelo económico liderado por las universidades, leamos a Rodríguez (1999).

..." contribuir a que los países cuenten con las capacidades científicas y tecnológicas suficientes para competir en una economía mundial globalizada; crear los cuadros profesionales y técnicos que la renovación de las estructuras de 
ISSN 1659-3316

Junio 2018-Noviembre 2018

Iza Villacís Víctor Adolfo

producción y de servicios del país está requiriendo; participar en el debate sobre temas que son cruciales para definir las opciones de política económica, de modelos de desarrollo social, de gobierno y participación ciudadana, entre otros. También le compete a la universidad de hoy anticipar y apoyar procesos de cambio en aspectos tales como la dinámica poblacional, el empleo, la distribución de los servicios de salud y educación, la impartición de justicia y el respeto a los derechos humanos, la preservación del medio ambiente y el patrimonio cultural nacional"

\section{Jóvenes y visión de ser}

En otro contexto los estudiantes llegan a la universidad dirigidos con la necesidad de acreditación y certificación para buscar un espacio laboral dentro de este sistema macroeconómico, las necesidades imperantes del sistema obligan a que los resultados vocacionales se liguen a una carrera que les propicie un empleo a través del cual puedan percibir un salario y establecerse dentro de la sociedad como un profesional. Los estudiantes al mismo tiempo sienten la necesidad de acreditar lo más antes posible mientras que la universidad sigue armando planes de estudio en pregrado para cuatro años y por semestres, fragmentando el estudio por partes. Situación que de cierta manera genera estabilidad institucional, pero que para los estudiantes de las nuevas generaciones es poco llamativo ya que la velocidad y la satisfacción inmediata son elementos claves, por lo que el estudio de esta manera resulta pesado y obsoleto.

Estamos frente a una sociedad juvenil en cambio constante, se ha pensado en jóvenes ahistóricos ligados a la inmediatez (Muñoz, 2013) que no necesitan fundamentación sobre lo que aprenden, cada vez más prácticos y pragmáticos necesitan contenidos funcionales y no significativos, lo que genera un profundo cambio en la manera de enseñar en el campo universitario. Los jóvenes en la actualidad son cada vez más pragmáticos, mientras sea útil el conocimiento y 
aplicable, no es necesario saber sus fundamentos, esto mismo pasa en la vida. El acceso a la historia personal como fundante de la persona, la historia nacional, regional, o de una región, así como la historia en su totalidad es casi innecesaria por decir lo menos.

Denominados como Millennials, la generación del siglo XXI, (Ferrer, 2010) tiene unas características totalmente distintas a los docentes de otras generaciones o del siglo anterior. Si bien es cierto los estudios acerca de esta generación se sitúan en Norteamérica, la situación es bastante similar en Europa y porque no decirlo en Latinoamérica aunque con sus variables temporales y culturales que generan unas buenas diferencias a ser estudiadas, los componentes más característicos posiblemente son como lo menciona Ferrer (2010) en su estudio de crecimiento y desarrollo inmerso en la era digital, posiblemente los medios tecnológicos son parte de su esencia, si se permite el agregado, así mismo una notable capacidad de civismo e identidad con grupos de pertenencia.

..."esta generación tiene comportamientos y formas de entender la vida que generan un mayor optimismo y una mejor consideración de sí misma en comparación con las dos generaciones anteriores. Investigaciones llevadas a cabo en 2006 indican que dos tercios de la población americana considerada generación millennial creen que sus vidas son "excelentes" o "muy buenas". (Ferrer, 2010)

Este positivismo puede traducirse también en el pensamiento de que todo está bien, no hay porque preocuparse, o toda pasará. El positivismo no como ciencia sino como emoción abarca una sensación de estabilidad y confort que se sobreponen a todo tipo de dolor, angustia o sufrimiento. Si yo estoy bien todo está bien.

Comprendiendo otra circunstancia estamos frente a una generación que por primera vez en la historia enseña a una generación pasada sobre las circunstancias tecnológicas que los adultos no pueden manejar o entender, situación que les pone en ventaja en la sociedad de la ciencia y la tecnología y 
que genera una actitud de servicio, pero también de distanciamiento. (Chavez, 2017)

Desde el mundo adulto-céntrico (Vásquez, 2013) como un elemento de poder que ha modelado sociedad, generaciones, culturas y racismos; y del sistema imperante, que en la actualidad ya no necesita de la ideología o la propaganda para manifestarse como estructuras sociales manipuladoras o coloniales, pues se empuja al ser a la explotación en especial a los más jóvenes desde los modelos educativos y aún más al entrar a la universidad, el sistema de profesionalización lleva a la persona a autoexplotarse para conseguir lo deseado, Byung - Chul Han (2017) lo manifiesta de manera contundente, "los tiempos en que existía el otro se han ido. El otro como misterio, el otro como seducción, el otro como eros, el otro como deseo, el otro como infierno, el otro como dolor va desapareciendo" (pág. 9) En este ambiente de autoexplotación del individuo la universidad se encuentra como parte del sistema, pues naturalmente los jóvenes deben trabajar para estudiar y pagar la universidad, o las mismas familias, los padres, tener un crédito alto el cual deben pagar mes a mes, para poder dar una educación superior a sus hijos que en estos momentos es casi obligatoria por el sistema, y que sigue en aumento, porque un tercer nivel no es suficiente, seguirá una especialización y doctorados. Esto cambia significativamente la comprensión de sí mismo, la comprensión del otro, o la comunidad humana, en estos momentos de la historia el ser humano busca sobrevivir a como dé lugar dentro de un supermercado de "oportunidades" que vende a la felicidad y el bienestar como mercancía, pero a cambio de la auto-explotación adherida como decisión personal o libertad. En esta circunstancia la universidad que busca la verdadera libertad del hombre deberá reflexionar sobre su papel formativo, y no solamente sobre su permanencia en el mercado como instituciones que se prestan al sistema para formar profesionales que necesita el mundo laboral y mercantilista en el cual nos desenvolvemos.

La base de las críticas al sistema educativo occidentalista es la manera de educar del siglo XIX y XX, un estilo prusiano, militarizado y disciplinar, con horarios, 
ISSN 1659-3316
Iza Villacís Víctor Adolfo

Junio 2018-Noviembre 2018

sirenas y pensum establecidos. Agregando a este estilo el panóptico de Bentham (2011), el ojo que todo lo ve y que no puede ser visto, usado primero en las cárceles y luego en la industria pasa a ser parte del control temible en las escuelas a través de inspectores.

El gran hermano de Orwell (1984), el estado vigilante y el sistema de prevención establecido como elemento de disuasión frente a los actos concupiscentes de la naturaleza humana. Estas prácticas en la base se han perpetuado. Los grandes y brillantes planes de innovación en un sentido o estilo metodológico 0 de infraestructura, incluso con pensum diferentes, no pueden llegar a concluir o al estar instalados necesitan necesariamente del control, el poder es necesario incluso para cuando se rompe modelos estacionarios, manipuladores o que van en contra de la libertad humana. Estamos parados en el umbral del miedo de las sociedades modernas que por seguridad entregan lo más alto, la libertad, hoy las cámaras de "seguridad" están en todo lugar y en todo espacio, se han disparado por doquier los sistemas de control, la sospecha, el temor, la angustia, el miedo frente al otro es latente. La audacia de la maldad no tiene límites y se disfraza de bien.

Los pedagogos que se muestran a favor de la centralidad de la persona, la educación liberadora de Freire, hoy es estrangulada por el temor a las armas que puede portar un estudiante, habrá que armar a los profesores como política de seguridad. Es que hemos perdido la batalla en contra de la violencia, la paz ya no es posible en los sistemas educativos. Montessori estaría horrorizada y el Fausto se lamentaría de su suerte.

La educación sigue y continúa siendo un sistema triangular con una punta de poder en la cima que establece los criterios, las reglas, los servicios y todo lo que pueda controlar. La educación está hoy ligada al sistema y ha sido puesta a su servicio. La universidad no se salva y menos en contextos donde el control del Estado se vuelve parte de la democracia. Cuando el sistema necesita controlar y

\section{(c) (i) (-)}

La Revista Estudios es editada por la Universidad de Costa Rica y se distribuye bajo una Licencia Creative Commons Atribución-NoComercial-CompartirIgual 3.0 Costa Rica. Para más información envíe un mensaje a revistaestudios.eeg@ucr.ac.cr. 
ISSN 1659-3316

Junio 2018-Noviembre 2018

Iza Villacís Víctor Adolfo

adormecer la conciencia de sus ciudadanos, la educación es una herramienta eficaz, económica y fuerte.

Este sistema que produce y provoca miedo, también genera sensación de fracaso, estados de ansiedad frente al futuro que condiciona la felicidad o el bienestar a una estado situacional de confort y recursos para sentirse seguros, se consideran para esto y para diferenciarse un buen plantel, una buena categoría social, un buen nivel de idiomas, parecería que mientras más caro es mejor y se busca alcanzar la calidad realizando y verificando procesos a través de la medición de estándares internacionales. Y todo en nombre de la persona, se justifica diciendo que es por su beneficio. El hecho de tener miedo al futuro y al fracaso profesional, alimenta la auto-explotación que deja de estar ligada a una ideología o aun sistema injusto, sino que, para poder sobrevivir, tener, consumir, mantener el status social se vive en neurosis constante para producir.

La gestión docente se ha desarraigo de los procesos formativos y humanos, los planes académicos, el pensum, contenidos analíticos y procesos de aprendizaje son el campo de batalla de la planificación y las evidencias. Solicitud de informes que no tienen nada que ver con la formación, acompañamiento y desarrollo de la persona se vuelven parte de la cultura organizacional en las instituciones sean públicas o privadas. Lo que perpetua el sistema y las categorizaciones, que no van ya en escala vertical sino en escala de acreditación. Aprobado o no aprobado, son los lenguajes educativos más frecuentes que buscan las Instituciones educativas por parte de organismos internacionales que muestran las mejores intenciones, pero en base a la competencia dentro de un mundo netamente capitalista y utilitarista.

La gestión docente se ha vuelto propia de la administración, abandonando la crítica filosófica, el desarrollo humano, la pedagogía como construcción del individuo, pues no hay tiempo. Ha pasado a evaluar y acreditar a estudiantes cada

\section{(C) $(00$}

La Revista Estudios es editada por la Universidad de Costa Rica y se distribuye bajo una Licencia Creative Commons Atribución-NoComercial-CompartirIgual 3.0 Costa Rica. Para más información envíe un mensaje a 
vez más alejados de los corazones docentes y desligados de lo que se quiere comercializar y marketizar como formación.

Así se llega a compenetrarse en sub-alteridades comunes que mantienen el drama de la indiferencia como un espejo imaginario frente al cual solo nos miramos a nosotros mismos y a los grupos a los que se pertenece. La mismidad no necesita de la otredad, porque se hace visible solo en quien se considera parte del grupo social al cual se pertenece. La identidad ha ganado la batalla del aprenderse a donar y al servicio. Todo se compra y todo se paga, no hay favor ni gratuidad, si hoy es dado mañana es cobrado.

El pensamiento contemporáneo de Byung Chul Han con respecto a la critica que realiza de la condición humana de la expulsión de lo distinto, y de una sociedad en cansancio (Han b. C., 2017) permanente y agotamiento por ser, permite un puente certero y propositivo frente a la situación de la indiferencia y a la misma alteridad entre iguales desde la crítica filosófica al Sistema y al ser que somos y hemos creado, el que ha sido "autor y creador de sí mismo" (pág. 56) abandonando cualquier tipo de intromisión de otredad. Esos círculos cerrados y parejos donde lo distinto, el diferente, el que no calza, no puede acceder a estos espacios y por lo tanto no disfruta de esa sub-alteridad creada en el pensamiento de los grupos. ¿Cómo salir de las sub-alteridades impuestas y complejas que responden a intereses comunes y que desde luego se manejan en un tipo de lenguaje y estado de la existencia? ¿En qué consistiría la actitud de hospitalidad y alteridad cuando según el número de Dunbar nos relacionamos entre 150 personas aproximadamente? ¿Es entonces la actitud de alteridad un imaginario que no exige ética sino con los que comparten aspectos comunes?

El número de Dunbar: "Esta cifra se refiere al número de contactos óptimo de cualquier red social. En 1992, el antropólogo británico Robin Dunbar llegó a la conclusión de que el poder cognitivo del cerebro limita el tamaño de la red social estable que un individuo puede establecer. Extrapolando los tamaños del cerebro

\section{(C) $(\Theta \odot$}

La Revista Estudios es editada por la Universidad de Costa Rica y se distribuye bajo una Licencia Creative Commons Atribución-NoComercial-CompartirIgual 3.0 Costa Rica. Para más información envíe un mensaje a 
ISSN 1659-3316
Iza Villacís Víctor Adolfo

Junio 2018-Noviembre 2018

y las redes sociales de los primates, sugirió que el ser humano puede tener redes estables de alrededor de ciento cincuenta contactos".

Este número establece un estado que condiciona al ser humano desde su naturaleza biológica a 150 personas. Entonces, sería posible pensar que ¿la alteridad es un elemento que se da y se constituye en una actitud de amabilidad y de atención comportamental para aceptar a todos aquellos que no son de círculo de aceptación social?

Realmente expulsamos a lo distinto, o es que naturalmente nos relacionamos con aquellos con los cuales nos parecemos por ideas, intereses, trabajo, gustos, etc... podemos realmente ser conscientes de la indiferencia que nos genera el hecho de no poder tener un círculo social más amplio y más complejo por lo que es necesario mantener al alteridad como sub - alteridad para el grupo en el cual nos desenvolvemos y presentarnos con amabilidad en actitud de alteridad que se encaminan a equilibrar relaciones menos angustiantes.

Lo que se acepta es la diversidad y la tolerancia se vuelve un mecanismo de olvido y de poder. ¿quién tolera a quién? Aquel que se alza con su verdad, en su propio poder, autor y creador de si mismo en el ego, una verdad que la ve como cierta, de manera subjetiva simplemente y frente al otro, que también tiene su verdad, y no tiene el poder sobre el otro, el extraño, el extranjero, entonces debe ser tolerada, y en ese caso el asunto queda neutralizado. La tolerancia olvida, invisibiliza, detesta, genera indiferencia e inmoviliza. No hay otredad en la tolerancia. No hay alteridad, hay un breve gesto de cortesía.

Hacia el desarrollo de la persona y la alteridad

Muy de a menos está la alteridad con respecto a involucramiento o respuesta frente al otro, al vulnerable, al rostro que nos impulsa a su defensa. Cada vez la indiferencia, el subjetivismo y la cosificación generan un ensimismarse en la angustia por ser o llegar a "ser". Es una estructura social que amenaza a la alteridad con una sensación de vacío y de independencia total del otro que no es meramente psicológica sino que raya en la soledad y el abandono. Las

\section{(c) (i) (2)}

La Revista Estudios es editada por la Universidad de Costa Rica y se distribuye bajo una Licencia Creative Commons Atribución-NoComercial-CompartirIgual 3.0 Costa Rica. Para más información envíe un mensaje a 
ISSN 1659-3316

Junio 2018-Noviembre 2018

Iza Villacís Víctor Adolfo

sociedades modernas cada vez más conglomeradas, encerradas en sus muros de la "seguridad" y el miedo, así como la sospecha más inaudita, han encerrado en muros a ciudadelas, departamentos, sectores buscando exclusividad. La sensación de la mismidad se manifiesta en lo igual. Mientras más iguales mejor, no hay angustia, ni dicotomía. No hay solo nausea (Sartre) si no vomito (Han, 2017).

La indiferencia va ganando terreno en una sociedad angustiada, donde la droga más efectiva es el consumo y la expresión de la ansiedad es la auto-explotación. El otro ha sido silenciado, su grito en nuestro rostro ya no se escucha. Los auriculares son la mejor compañía para callar la voz del otro y autoexiliarse del presente. La relación es cyber, a través de la red. La mirada a los ojos se vuelve la ventana que no deseo mirar y que tampoco se puede acercar para ver. Mirar adentro del otro es un cansancio atroz porque mirar compromete, cuestiona, violenta, calla, desquicia y a la vez alimenta, en una sociedad anoréxica mirar al otro es hastío y hartazgo, más al mirar el sí mismo responde, se hace responsable por el otro, es decir su mirada, su rostro, su presencia, su cuerpo, su voz, arrebata de mí una respuesta que por ahora es la indiferencia y la espalda. Aprender a responder es vital para la humanidad porque significa responsabilidad, he aquí la muestra de una propuesta de Levinas que aumenta el sentido de la palabra y la trasciende. Cuando el ser responde por el otro se transciende a sí mismo, porque no solo se hace cargo de sus actos, sino que se hace cargo del otro solo por ser en el otro, se hace cargo, responde por el otro desde su invalidez, desde su invisibilidad a la cual le ha llevado el sistema impuesto y atroz, responder es hacer "miserable" con el otro, porque se lo rescata en su desvalidez, en su vulnerabilidad. Esta respuesta que como bien lo explica Lévinas, el filósofo lituanofrancés, desde la totalidad (el yo) descubrir el infinito, infinito que es el otro4. Responder es alimentar la necesidad del otro de sí mismo, es la vulnerabilidad de la mirada, es descubrir la propia vergüenza que nos hace humanos y vulnerables, es descubrir que el otro no vale porque el yo le da valor sino porque el otro me

\section{(c) (i) (2)}

La Revista Estudios es editada por la Universidad de Costa Rica y se distribuye bajo una Licencia Creative Commons Atribución-NoComercial-CompartirIgual 3.0 Costa Rica. Para más información envíe un mensaje a 
descubre mi miseria y mi propia valía, por eso la mirada cuando juzga es juzgada, cuando ama es amada, cuando hiere es herida, la otredad en alteridad no es un juego de "tronos" o lucha de contrarios, no es tolerancia, como mal menor, es la profundidad del amor, que puede ver unos ojos y decir te amo, entendiendo y sabiendo que quien ama es el Otro, con mayúsculas habitándolo y cuando alguien dice que te ama, ese ser ha trascendido en la verdad y la luz, ha sido excedido en su totalidad por el Infinitamente Otro que le habita para darse, donarse, establecerse, morar, revelarse. Cuando el amor es de verdad se asume al otro en toda su condición y se habita haciendo posible lo de la unión hipostática natural del hombre y la mujer, "juntos serán una sola carne" porque solo en el amor como ética se puede decir "esta es hueso de mis huesos y carne de mi carne", tenía razón al descubrir la esencia del amor en el hecho de observar al observador, el método para la comprensión permanente del yo frente al ego. "Cuando uno ama a su hijo, ama en él a todos los niños del mundo" (Krishnamurti, 2003), el amor es la trascendencia que nos permite ir más lejos de lo que nuestras manos pueden tocar, nuestros ojos ver, nuestros sentidos sentir. Nos arrebata a otra realidad en la que existe "otro modo que ser" (Levinas E. , 1987)

Pasar del sí mismo al otro es un acto de rebeldía y valentía, pero también un acto de amor por sí mismo para redimirse, salvarse, volver a ser uno mismo.

De rebeldía porque es necesario romper con lo establecido, incluso considerado como bueno. Porque la falta de moral fundamental hoy hace que se llame bueno a cualquier cosa, aunque no tenga categorías de bien o de bondad. Todo parecería bueno, todo parece que está bien, por lo tanto, no afecta a la moralidad. No hay angustia por la moral. La angustia viene por la carencia para no seguir consumiendo, no poder seguir comprando, cambiar el modelo del auto, del celular, de la casa. La angustia se manifiesta en sensación de pobreza, vacío en los bolsillos o en la cuenta del banco como angustia del ser. La angustia frente a la falta de señal de datos o de la batería, la angustia ya no es frente a la muerte sino

\section{(c) (i) (-)}

La Revista Estudios es editada por la Universidad de Costa Rica y se distribuye bajo una Licencia Creative Commons Atribución-NoComercial-CompartirIgual 3.0 Costa Rica. Para más información envíe un mensaje a 
al no disfrute total e inmediato. El culmen de la alegría es viajar, disfrutar, pasear, aunque luego se esté pagando a cómodas cuotas hipotecando la vida y el tiempo.

De valentía porque hay que tener la humildad para pasar del sí mismo egoísta e indiferente a la alteridad como respuesta por y en el otro, es un acto de valentía el asumir la vida en otras categorías. El ir más allá de la esencia (Levinas E. , 1987) como acto de trascendencia en la actualidad es un acto de valentía. Al acto, a la acción Levinas le dice Obra: "La Obra pensada hasta el fondo exige una generosidad radical de lo Mismo que en la Obra se dirige hacia lo Otro" (Levinas E. , 1967) y no hay retorno, no hay gratitud, no es necesaria. El acto de ir hacia el Otro, la Obra no desea nada del otro.

Una situación existencial que se redime con sentido, involucrando al ser en una para qué, un motivo para vivir, para existir, para crecer y desarrollarse con mayor profundidad que el profesionalizarse como el sistema lo exige. No basta entonces hacer lo que dice el mundo o seguir la senda supuestamente correcta que la sociedad consumista, pragmática y utilitarista presenta. Es necesario y es urgente que la persona se provoque a sí misma un tipo de desarrollo totalmente diferente. Una valoración de su propio ser desde otras categorías existenciales como el valor del encuentro, la comunión, la gratitud, la gratuidad, la hospitalidad, la bondad.

La alteridad pierde fuerza de desarrollo en humanidad al individualizar al sujeto en un "ontocentrismo" inadecuado y absurdo. Recuperar la alteridad, es descubrir al otro que me habita, descubrir el rostro, el cual como lo manifiesta Levinas, no es un rostro, ni unos ojos, ni una silueta concreta. El otro no solo es el vulnerable, es todo individuo y todo ser vivo que habita el planeta. La regla Budista entregada por Shidarta Gautama seis siglos antes del nacimiento de Cristo, ya tomaba en cuenta esta necesidad absoluta para que la humanidad camine prósperamente hacia la plenitud: respetar todo tipo de existencia. En un diálogo budista posterior lo encontramos así:

"Esta Ley [que es inherente al universo] es la causa de todos los fenómenos y es la realidad que se convierte en el principio básico que mantiene una estricta

\section{(c) (i) (2)}

La Revista Estudios es editada por la Universidad de Costa Rica y se distribuye bajo una Licencia Creative Commons Atribución-NoComercial-CompartirIgual 3.0 Costa Rica. Para más información envíe un mensaje a revistaestudios.eeg@ucr.ac.cr. 
armonía entre todos los fenómenos. Creo que el pulso del universo, que se basa en la Ley, es la misericordia ('jihi', en la terminología del budismo japonés) o, para emplear el término occidental, el 'amor', que se esfuerza en crear y preservar la armonía entre todas las cosas". (Matsuoka, 2005)

Cristo nos da en sí mismo el modelo de existencia en rebeldía y valentía, con el amor y la misericordia como esperanza de un sentido nuevo a la Ley. La compasión no es el lenguaje de los débiles como afirma Nietzsche. Es el lenguaje más alto de humanidad. Como si fuera paradójico, lo débil te hace fuerte. En la derrota está la salvación. Es tan fuerte su compromiso para quien decide seguir el modelo anunciado por Cristo que advierte será perseguido, vituperado, maldecido. Respeto y aceptación, respuesta frente a la situación actual, responsabilidad desde otro punto de vista. Es vital comprender y recuperar que las tradiciones milenarias al presentar la misericordia como base del amor, no es un aspecto retrogrado como parecería entenderse en la actualidad, es parte del desafío humano.

He aquí entonces dos categorías que le son esenciales a la perspectiva de Levinas, la substitución y la trascendencia. Es decir que para que exista misericordia, también es necesario tener presupuestos claros para una ética como filosofía primera. El ser necesita ser contemplado para ser amado, no solo mirado, visto $u$ observado, es necesario contemplar y solo cuando se ama se puede contemplar, se puede perder la mirada en el amado. Contemplar es detenerse, atreverse a perder el tiempo. Se puede substituir. Substitución que no se introduce a vivir "por el otro" no se puede substituir al otro en su respuesta, o en su propia existencia. El tratado que hace Derrida, por supuesto con su intencionalidad de comprender los conceptos para su propuesta de deconstrucción, devela muy bien el asunto de la sustitución desde conceptos de acogida y hospitalidad. "la hospitalidad es aquello que se abre hacia el rostro, lo que lo acoge: el rostro siempre se entrega a una acogida y la acogida acoge solamente a un rostro" (Conesa, 2006)

\section{(c) (i) (-)}

La Revista Estudios es editada por la Universidad de Costa Rica y se distribuye bajo una Licencia Creative Commons Atribución-NoComercial-CompartirIgual 3.0 Costa Rica. Para más información envíe un mensaje a 
ISSN 1659-3316

Iza Villacís Víctor Adolfo

Cuando se contempla se acoge, inicia una actitud de acogida, que no es un mero hospedaje. La fuerza de la mirada es la contemplación que trasmuta al ser a un espacio atemporal (trasciende) y a un recuerdo memorial. El amor puede ser visto al contemplar. La substitución solo admite desde el amor que se mira a sí mismo en lo contemplado.

Entonces la alteridad se muestra como contemplación del otro, como redención y conocimiento del infinito, de lo totalmente Otro.

La trascendencia es infinita en el otro que sostiene la totalidad de mi ser. Estos desafíos de Levinas al pensamiento son exhaustivos porque unen al ser hacia una realidad que no se sostiene sino en una tradición que ve a Dios como el totalmente Otro, a quien no le es necesario la vida humana o de cualquier especie para su existencia. Su libertad no está en correspondencia con la nuestra y sin embargo en sí mismo modela la existencia de quienes serán sus amados. Si el hombre ama es porque Dios lo ha trascendido. No somos nosotros quienes trascienden hacia Dios porque Él, totalmente Otro no nos necesita. En su infinita misericordia nos contempla y nos habita, nos trasciende sale de sí mismo, desde su totalidad y su infinitud. (Levinas E. , 1987) Es por eso que el lenguaje de la trascendencia es lenguaje de amor, palabra que habita en el acontecer de la compasión y la misericordia, de la excedencia y de la substitución, somos la otredad frente a Dios que asume para amar de forma extraordinaria, asume nuestra vulnerabilidad y al mirarnos se detiene, cumple su propio mandamiento en nosotros: el no matarás, se vuelve amor y misericordia. El ser trasciende en su finitud por el amor que habita y que puede hacerse visible por el mismo ser que saliendo de si asume su propia vulnerabilidad en la vulnerabilidad del otro.

\section{(c) (i) (9) (2)}

La Revista Estudios es editada por la Universidad de Costa Rica y se distribuye bajo una Licencia Creative Commons Atribución-NoComercial-CompartirIgual 3.0 Costa Rica. Para más información envíe un mensaje a 


\section{Bibliografía}

Acevedo, J. (2010). La frase de Heidegger "la ciencia no piensa", en el contexto de su meditación sobre la era técnica. Scielo, revista de filosofia volumen 66, $5-23$.

Aguirre, J. (2010). Sufrimiento, verdad y justicia. Alpha (Osorno), 169 - 180.

Bauman, Z. (2007). Tiempos liquidos. Madrid: Tusquets.

Begnini, R. (1997). La Vita è bella [Película]. (Dirección).

Behtham, J. (2011). El panóptico. Mexico: circulo de bellas artes.

Chavez, V. H. (2017). Tecnología, educación y nuevas generaciones . Los jovenes y la tecnología (págs. 34 - 39). Guayaquil: Senderos.

Chomsky, N. (2016). La (des) educación. Critica.

Conesa, D. (2006). La «Ética de la acogida» en el pensamiento de Emmanuel Levinas. Una lectura derridaiana THÉMATA. Revista de Filosofía. Núm. 36, 56-72.

Cresto, E. (1997). Escepticismo, verdad y confiabilidad. Revista latinoamericana de filosofia , 93 - 125.

Emanuel, L. (1961). Totalité et infini. Essai sur l»extériorité. la Haya: Sígueme.

Ferrer, A. (2010). Millennials, la generación del siglo XXI. Nueva Revista UCA, 56 63.

Foucault, M. (1996). De lenguaje y literatura. Madrid: Iberica.

García, J. C. (2010). SUFRIMIENTO, VERDAD Y JUSTICIA. Alpha n.30 Osorno, $169-180$.

Garcia, X. (2004). El recorrido por el hombre del siglo XXI. Madrid: Salterrae.

García-Baró, M. (2007). La compasión y la Catástrofe. Salamanca: Sígueme.

García-Baró, M. (2010). El desafío de Levinas. Biblioteca virtual Miguel de Cervantes, universidad Complutense, 4 - 17.

Gimenez, A. (2011). Emanuel Levinas: Humanismo del Rostro. Escritos, 337 - 349.

Han, B. C. (2017). La expulsión de lo distinto . Barcelona: Herder.

Han, b. C. (2017). La sociedad del cansancio. Madrid: Herder.

Heidegger, M. (1927). El Ser y el Tiempo. Madrid: Editorial Trotta.

\section{(c) (i) (2)}

La Revista Estudios es editada por la Universidad de Costa Rica y se distribuye bajo una Licencia Creative Commons Atribución-NoComercial-CompartirIgual 3.0 Costa Rica. Para más información envíe un mensaje a 
Heidegger, M. (2009). De la esencia de la Verdad. Madrid: Herder.

Krishnamurti, J. (2003). Verdad y realidad. Madrid: Kairos.

Levinas, E. (1967). La trace de l'autre, en découvrant l'existence avec Husserl et Heidegger. Paris: Vrin.

Levinas, E. (1987). De otro modo que ser más allá de la esencia. Barcelona: Sígueme.

Locatelli, B. M. (2013). De Heidegger a Levinas. Una redefinición de la facticidad del Dasein. Buenos Aires: Instituto de investigaciones Gino Germani.

Matsuoka, M. (2005). La concepción del budismo sobre el ser humano. The Journal of Oriental Studies (Revista de Estudios Orientales), vol. 15, 86 102.

Medina, J. (2017). Decir en Griego la novedad del Hebreo. Zaragoza: Riopiedras.

Muñoz, A. (2013). El tiempo subjetico de los jovenes. En C. Mingote, El malestar de los jovenes (pág. capitulo II). Madrid: Diaz de Santos.

Ortiz, R. (1984). Historia de la filosofia. Oviedo: Pentalfa.

Orwell, G. (1984). El gran hermano te vigila. Madrid: Planeta.

Silva, W. y. (2017). Alteridad y Formación . Bogotá: Universidad de San Buenaventura,.

Vásquez, J. (2013). Adultocentrismo y juventud. Aproximaciones foucaulteanas. Sophia, UPS Ecuador No. 15, 217-234.

Watson, P. (2012). Historia Intelectual del Siglo XX. Barcelona: Crítica.

\section{(c) (i) (2)}

La Revista Estudios es editada por la Universidad de Costa Rica y se distribuye bajo una Licencia Creative Commons Atribución-NoComercial-Compartirlgual 3.0 Costa Rica. Para más información envíe un mensaje a 